ISSN 1823-626X

\title{
Journal of Fundamental Sciences
}

available online at http://jfs.ibnusina.utm.my

\section{Radiation induced emulsion grafting of glycidyl methacrylate onto high density polyethylene: A kinetic study}

\author{
Mohamed Mahmoud Nasef and Indriani Andromeda Sugiarmawan \\ Department of Chemical Engineering, Faculty of Chemical Engineering, Universiti Teknologi Malaysia, 81310 UTM Skudai, Johor, Malaysia
}

Received 2 February 2010, Revised 29 May 2010, Accepted 7 June 2010, Available online 26 June 2010

\begin{abstract}
Emulsion graft polymerisation of glycidyl methacrylate monomer onto high density polyethylene (HDPE) resin was studied. The radicals required to initiate the reaction were produced in HDPE resin by irradiation with the electron beam accelerator at ambient and vacuum conditions. The grafting reaction of GMA with irradiated HDPE was initiated by emulsion method using Tween 20 as a surfactant and water as a solvent under controlled conditions. The kinetic behavior of grafting reaction was investigated with respect to the degree of grafting under various parameters i.e. monomer concentration, radiation dose, grafting temperature and surfactant concentration. The degree of grafting was found to be a function of the investigated parameters. Particularly, surfactant concentration in the emulsion was found to be crucial for determining the micelle size and eventually the degree of grafting. The order of dependence of the initial rate of grafting on the monomer concentration and the irradiation dose was found to be 0.94 and 0.60 , respectively. The initial rate of grafting was also found to increase with the increase in the grafting temperature varied in the range of $308-333 \mathrm{~K}$. The optimum reaction parameters required to obtain desired and reproducible degrees of grafting in the resin could be identified. Moreover, the emulsion radiation grafting method was found to offer essential advantages over the conventional grafting with solvents including low radiation dose, less monomer concentration and cost effectiveness.
\end{abstract}

| Radiation graft polymerisation | Emulsion | Kinetics | Glycidyl methacrylate |

( 2010 Ibnu Sina Institute. All rights reserved. http://dx.doi.org/10.11113/mjfas.v6n2.189

\section{INTRODUCTION}

Radiation-induced graft polymerization is a widely used method to produce high performance chemically active polymer materials for adsorption and separation processes on the basis of various commercial polymers available in different forms (films, fibers, resins, textiles, powders) [1]. This method offers an alternative way to combine two highly incompatible polymers and retain the desirable properties of the polymeric components [2,3]. Besides, it also offers the ability to closely control the graft copolymer compositions and properties by selection of suitable grafting conditions [2].

In such graft polymerization, the monomer of glycidyl methacrylate (2,3-epoxypropyl methacrylate) has attract high interest due to its epoxy group that can be modified into various functional groups. Figure 1 shows the reaction of radiation grafting of GMA onto HDPE. GMA have been develop to different type of polyethylene trunk polymer, such as films [4], fibers , non woven fabric and hollow fibers [5-7]. Besides, radiation grafting of GMA on material made of polypropylene coated with polyethylene also can be achieved [8-9]. However, those paper mostly used low density polyetylene (LDPE) as the polymer base.

Corresponding author at: Dept. of Chemical Eng., Fac. of Chemical Eng.

Universiti Teknologi Malaysia,81310, UTM Skudai, Johor, Malaysia.

E-mail addresses: mahmoudeithar@ic.utm.my
Generally GMA can be grafted by radiation induced graft copolymerisation using organic solvents such as methanol [5,7, 10-12] methanol and water solution [13], ethanol [14], dimethyl sulfoxide [9], and acetone [15]. However, instead of grafting GMA on organic solvent this monomer can be emulsified by surfactant in water and can be grafted onto the trunk polymer. From economical perspective, this technique found to be more efficient compared with grafting with normal solvent. Under a proper chosen condition of emulsion, the radiation chemical yield of emulsion polymerization can attains very high values.

The characteristics of radiation induced graft polymerization by emulsion give more advantages compared to other methods [16], as follows: (1) Radiation induced graft polymerization by emulsion requires low dose rates and low absorbed dose. (2) Emulsion polymerization is carried out in water as dispersion medium. (3) The efficiency of radiation emulsion is much higher than the polymerization in bulk or suspension. (4) In industrial scale, emulsion polymerization waste water can be recycled directly after isolation without any purification.

Seko group $[4,16]$ studied GMA radiation grafting by emulsion into polyethylene fiber with different surfactants. However, there is no study about radiation induced grafting of GMA onto HDPE resin through emulsion route. In this work, the grafting onto HDPE resin was investigated in the 
emulsion of GMA. The kinetic of irradiation dose, monomer concentration and effect of temperature was also investigated. The evidences of the grafted resin were studied using FTIR.

\section{EXPERIMENTAL}

High Density Polyethylene (HDPE) resins, obtained from Polyethylene Malaysia were used as the polymer base. Glycidyl Methacrylate (GMA) was purchase from Fluka and used without any purification. Polyoxyethylene sorbitan monolaurate (Tween-20, termed Tw-20) were supplied from Sigma-Aldrich were used as surfactant.

The HDPE resin was grained into 400-650 $\mu \mathrm{m}$ size. Then, $5.00 \mathrm{~g}$ of HDPE resin were put into polyethylene bag and displaced the air in the bag with nitrogen. This bag was irradiated with electron beam $(2 \mathrm{meV}, 1 \mathrm{~mA})$ with the total dose of 10-40 kGY at room temperature.

The GMA emulsion was prepared by adding GMA into Tw-20 aqueous solution of concentration range from $0.1 \%$ to $10 \%$ until the concentration of GMA become 2$12 \%$. This emulsion was stirred at room temperature for 1 hour and dearated with nitrogen gas.
The obtained emulsion of GMA was sucked into the evacuated glass ampoule in which the irradiated HDPE resins were transffered. The glass ampoule was heated in the oven at different temperature ranging of $35-60^{\circ} \mathrm{C}$ to initiate the graft polymerization. After grafting reaction completed, the grafted HDPE resins were taken out of the glass ampoule and rinse with disstilled water and methanol to remove residual monomer and homopolymer. After being dried under vacuum in oven, the amount of GMA grafted onto HDPE resins was evaluated by the degree of grafting (Dg) using equation (1).

Degree of grafting $=\frac{W_{g}-W_{o}}{W_{o}} X 100 \%$

The grafted resin were characterized by FTIR (Perkin Elmer System 2000) spectroscopy. The original and grafted resins were hot pressed at $110^{\circ} \mathrm{C}$ to form into films the FTIR spectroscopy analysis.

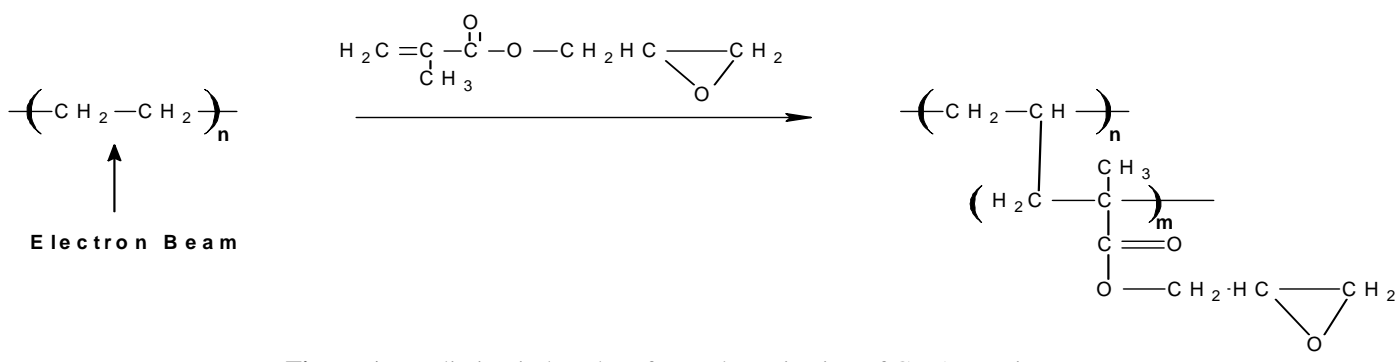

Figure 1: Irradiation induced graft copolymerization of GMA reaction

\section{RESULTS \& DISCUSSION}

Preparation of HDPE resins were carried out in two steps. Firstly, HPDE resin will be irradiated with electron beam. Secondly, GMA emulsion will be grafted onto irradiated HDPE resin under various condition. The degree of grafting calculated gravimetrically from the weight before and after grafting. The experiment was investigated under various parameter include surfactant concentration, irradiation dose, monomer concentration and grafting temperature.

To investigate the effect of surfactant concentration, GMA was grafted on HDPE resin with 30 Kgy irradiation at $10 \%$ GMA. The effect of surfactant concentration is shown in figure 2.The increament of Tw-20 concentration from $0.1 \%$ to $0.7 \%$ at $10 \%$ of GMA lead to increase degree of grafting. However, $0.5 \%$ of surfactant concentration provides longer emulsion stability compared to $0.7 \%$ of $\mathrm{Tw}$ 20.

The study of the effect of radiation dose on the graft polymerisation was carried out at $60^{\circ} \mathrm{C}$ in $10 \% \mathrm{GMA}$ emulsion with $0.5 \% \mathrm{Tw}-20$. The degree of grafting were investigated with different irradiation dose ranging from 10 to $40 \mathrm{Kgy}$ as a function of reaction time as shown in figure 3. For all doses as time increase the degree of grafting increases. Degree of grafting is dectated by the amount of radicals produced in the irradiated polyethylene resins. Therefore, increment of irradiation dose should lead to the increment of degree of grafting. The degree of grafting value after 5 hour reach $43 \%, 63 \%, 91 \%$, and $102 \%$ at dose of $10,20,30$, and $40 \mathrm{Kgy}$, respectively. The maximum degree of grafting occured at $40 \mathrm{Kgy}$. This trends showed a good agreement with Seko et al. (2007) upon grafting of GMA onto PE fiber by emulsion.

The effect of monomer concentration was investigated at range $2-12 \%$ of GMA. The relationship between the monomer concentration and the degree of grafting at $30 \mathrm{Kgy}$ is shown at figure 4 . The degree of grafting increases with the increase of GMA concentration until reaches its maximum concentration at $10 \%$. While above $10 \%$ GMA concentration, degree of grafting slightly decreases. This phenomenon happens due to fast initial reaction rate of grafting followed by slow reaction due to the lower monomer concentration and the reduction on number of active sites on the polymer background [18]. Choi and Nho (1999) and Nava-Ortiz et al. (2009) also 
reported the same trend that degree of grafting tend to decrease after reach the maximum level of monomer concentration

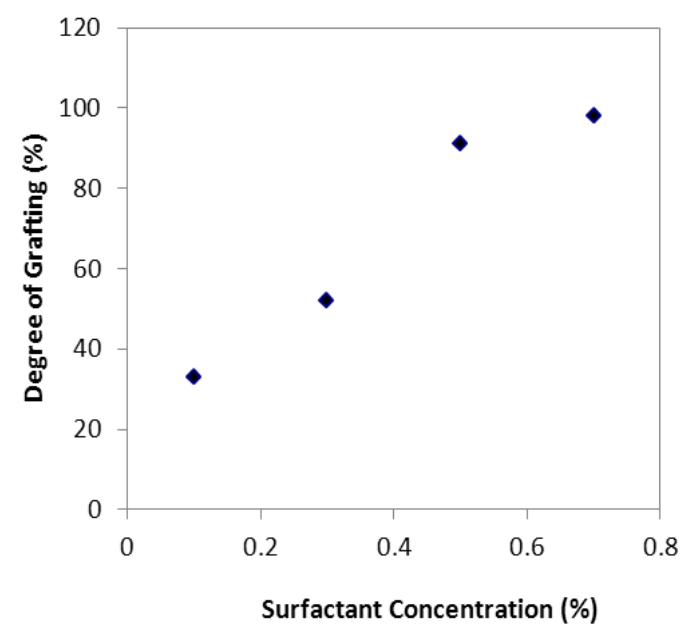

Figure 2: Effect of surfactant concentration.

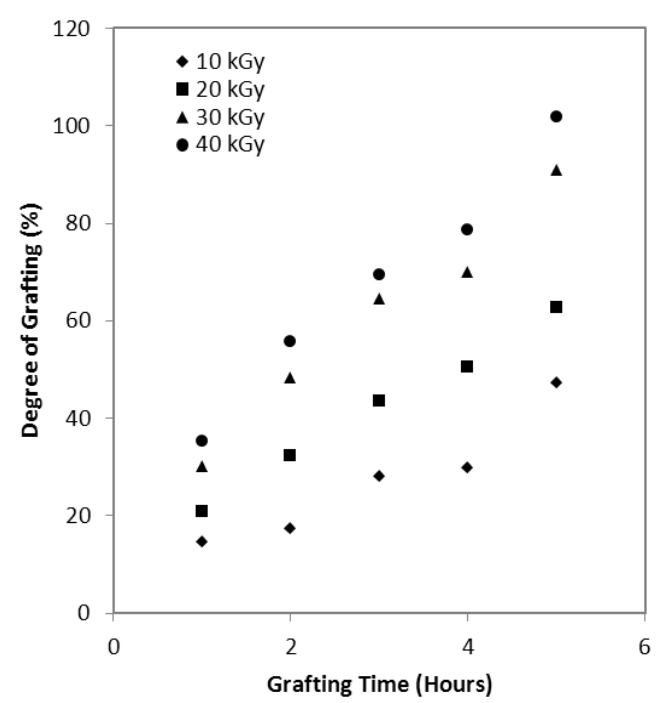

Figure 3: Effect of irradiation dose. Grafting condition: GMA concentration, $10 \%$; grafting temperature, $60^{\circ} \mathrm{C}$.

Kinetics of GMA radiation grafting by emulsion can be study by corelating function of monomer concentration and the irradiation dose. The following equation shows the relation of grafting rate with monomer concentration, radiation dose and surfactant concentration:

$\mathrm{Rg}=\mathrm{K}_{\mathrm{g}}[\mathrm{M}]^{\mathrm{a}}[\mathrm{D}]^{\mathrm{b}}$

where $R g$ is the initial rate of grafting (\% grafting/hour), $M$ is the monomer concentration (\% weigh), $D$ is the radiation dose (kGy) and $\mathrm{Kg}$ is the grafting rate constant.

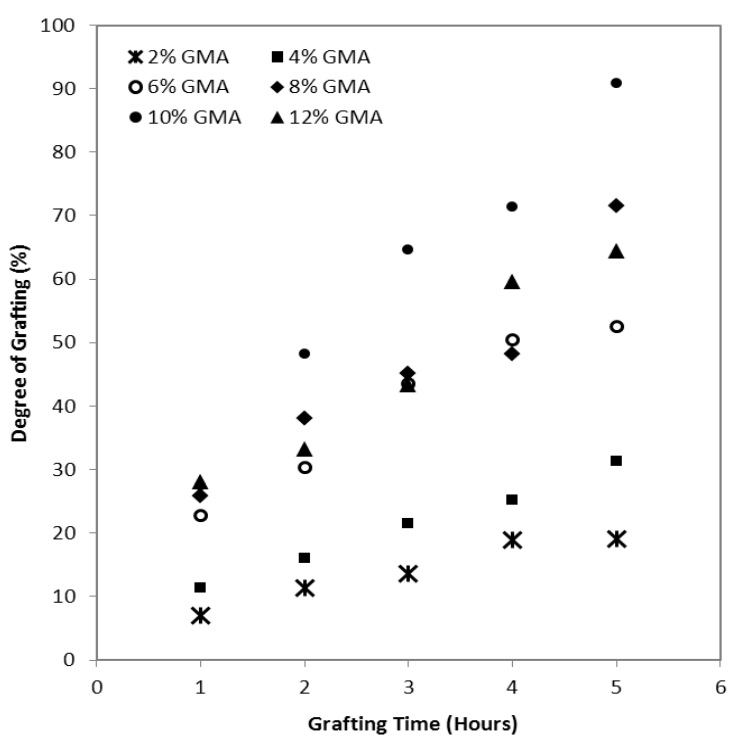

Figure 4: Effect of monomer concentration. Grafting condition: Irradiation dose, $30 \mathrm{kGy}$; grafting temperature, $60^{\circ} \mathrm{C}$.

The rate of polymerizarion ( $\mathrm{Rg}$ ) is calculated from the slope of the linear portion of the degree of grafting versus time plots. Values of parameters $a$ and $b$ were found by plotting the logarithmic initial rate of grafting $(\mathrm{Rg})$ for various GMA concentrations and irradiation doses. The values of $a$ and $b$ were found to be 0.94 and 0.60 respectively, which indicates that the grafting increases almost linearly with the concentration while increases parabolically with the irradiatin dose. The kinetic equation for the grafting of GMA onto HDPE by emulsion may be expressed as:

$\mathrm{G}=\mathrm{k}_{\mathrm{g}}[\mathrm{M}]^{0.94}[\mathrm{D}]^{0.60}$

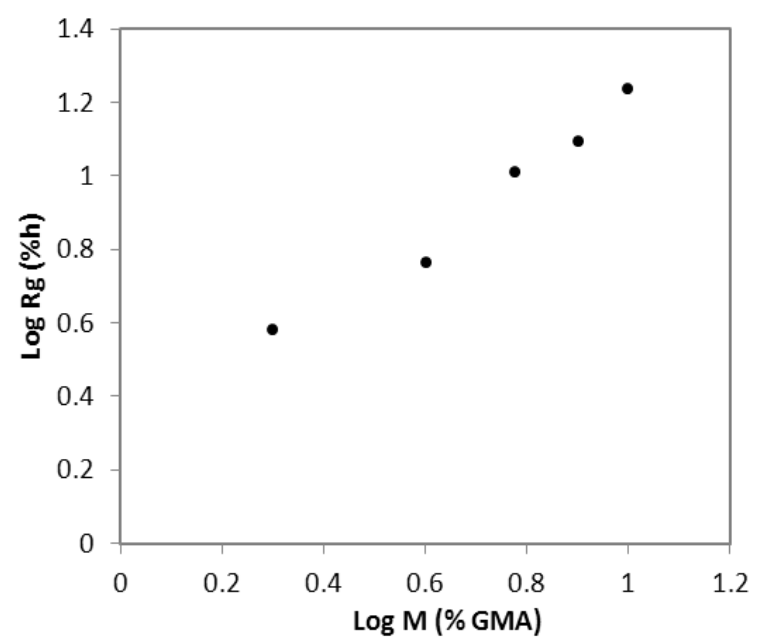

Figure 5: Log-log plots of grafting initial rates and monomer concentration. 


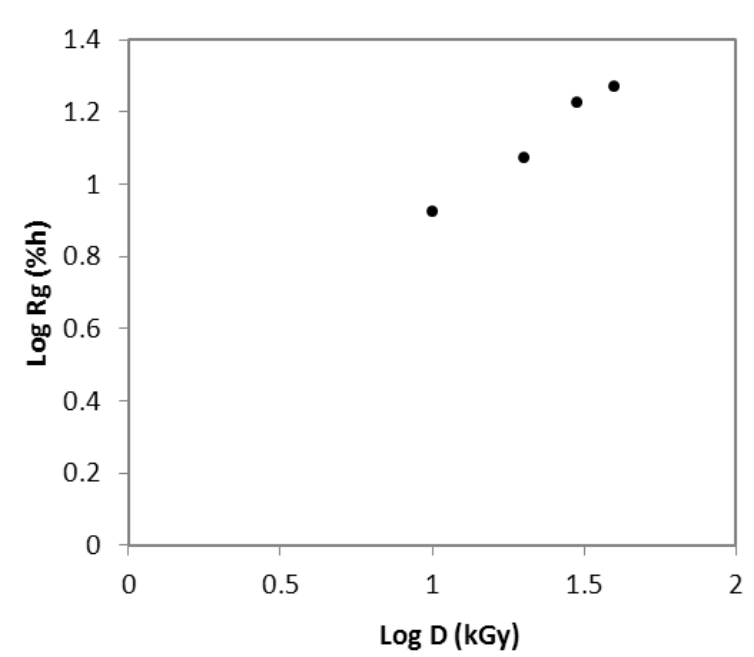

Figure 6: Log-log plots of grafting initial rates and irradiation dose.

Influence of reaction temperature of reaction on kinetics of copolymerization is extremely complex and can affect various characteristic in grafting system. Figure 7 shows the relationship between degree of grafting and the grafting time; having various grafting temperature. It is found that the increase of temperature leads to the increment of degree of grafting. The increment degree of grafting at higher temperature occurs because grating temperature improves the difussion of monomer into polymer matrix and also in the same time accelerates the decay radicals.



Figure 7: Effect of grafting temperature. Grafting condition: Irradiation dose, $30 \mathrm{kGy}$; monomer concentration: $10 \%$.
Arrhenius plots for radiation graft copolymerization of GMA onto HDPE resin are shown in figure 8. Arrhenius study can be calculated using equation as follow:

$\mathrm{K}=\mathrm{A} \mathrm{e} \mathrm{e}^{-\mathrm{Q} / \mathrm{RT}}$

Where $\mathrm{k}$ is the grafting rate constant, $\mathrm{A}$ is the preexponential rate constant, $\mathrm{Q}$ is the activation energy, $\mathrm{R}$ is the universal gas constant $\left(8.31 \mathrm{~J} \mathrm{~K}^{-1} \mathrm{~mol}^{-1}\right)$ and $\mathrm{T}$ is the absolute temperature. The relationship between $\ln \mathrm{G}$ and $1000 / T$ is linear at different temperatures. The slope of the linear equation gives the value of $\mathrm{Q} / \mathrm{R}$ and the intercept gives the natural logarithm of the preexponential rate constant A. From the calculation, the overall activation energy of emulsion grafting GMA onto HDPE was determined to be $31 \mathrm{KJ} / \mathrm{mol}$.

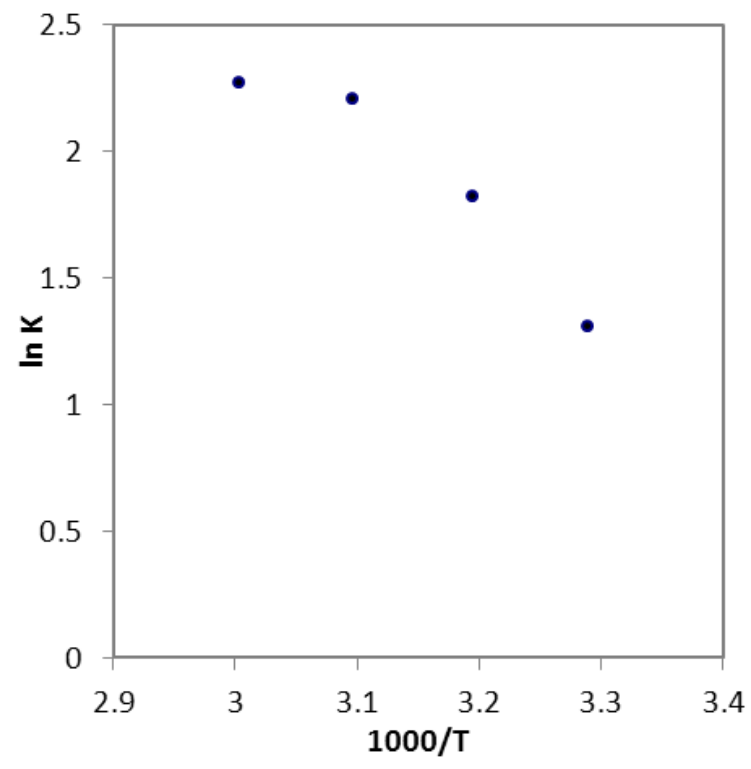

Figure 8: Arrhenius plot to the natural logarithm of the rate constant versus the inverse of the absoulute temperature.

Grafting of polyethylene onto HDPE particles were confirmed by FTIR spectral analysis. Typical FTIR spectra of the HDPE-g-GMA, GMA and original HDPE resins are shown in Figure 9. Compared to original HDPE particles, GMA spectrum and the spectrum of the GMA grafted HDPE (HDPE-g-GMA) resins at different grafting degree $39 \%, 65 \%$ and $91 \%$. The $\mathrm{CH}_{2}$ absorption bands of the $\mathrm{PE}$ resins appear at 2915 and $2847 \mathrm{~cm}^{-1}$. The GMA spectrum shows the $-\mathrm{C}=\mathrm{O}$ stretching vibrations bond of ester on 1718 $\mathrm{cm}^{-1}$ and the $\mathrm{C}-\mathrm{O}$ bond at band 1168 and $1256 \mathrm{~cm}^{-1}$. The band at 950-815 and $762 \mathrm{~cm}^{-1}$ also attributed to the epoxy ring of GMA. The GMA grafted HDPE are showing $\mathrm{CH}_{2}$ band at 2916 and $2848 \mathrm{~cm}^{-1}$ and ester group attributed by $\mathrm{C}=\mathrm{O}$ stretching vibration bond and $\mathrm{C}-\mathrm{O}$ bond at band 1724 , 1256 and $1148 \mathrm{~cm}^{-1}$. 


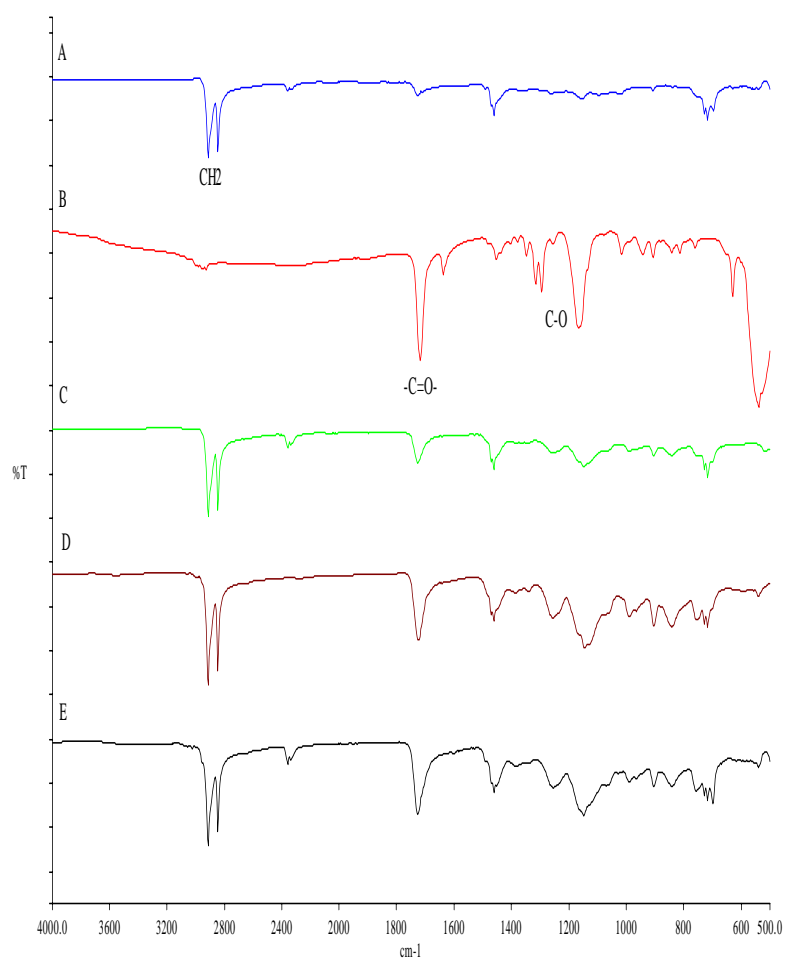

Figure 9: FTIR analysis of (A) HDPE, (B) GMA, (C) HDPE-g-PGMA Dg 39\%, (D) HDPE-g-PGMA Dg 65\% and (E) HDPE-g-PGMA Dg 91\%.

\section{CONCLUSION}

GMA is a well known monomer which can be grafted onto various polymer types using organic solvent. On the other hand, instead of the organic solvent, GMA can be emulsified by surfactant to be grafted in aqueous system onto HDPE resin. The degree of grafting was found increased with the increment of preirradiation dose up to 40 $\mathrm{kGy}$. The degree of grafting increases with the increase of GMA concentration until reaches its maximum concentration at $10 \%$, then the degree of grafting slightly decreases after that. The order of dependence of the initial rate of grafting on the monomer concentration and the irradiation dose was found to be 0.94 and 0.60 , respectively. The emulsion radiation grafting method was found to offer essential advantages over the conventional grafting with solvents including low radiation dose, less monomer concentration and cost effectiveness. The GMA grafted HDPE resin were prepared as precusor cation resin for heavy metal removal application.

\section{ACKNOWLEDGEMENT}

We acknowledge financial support from the Ministry of Science, Technology and Innovation of Malaysia for the grant of Development of Cation Exchange Resin for Removal of Heavy Metals from Industrial Waste Water Using Locally Produced Polyethylene.

\section{REFERENCES}

[1] S. W. Lee, Y. Bondar, D. H. Han, React. Funct. Polym., 68 (2008) 474-482.

[2] M. M. Nasef, H. Saidi, H. M. Nor, K. Zaman, M. Dahlan, J. Appl. Polym. Sci., 73 (1999) 2095-2102.

[3] M. M. Nasef, (2008). Separation and Purification, In: Eds. A. Battacharya, J. W. Rawlins, P. Ray, Grafting and Crosslinking of Polymers, New Jersey: John Wiley and Sons.

[4] ～N. Seko, L. T. Bang, T. Tamada, Nucl. Instrum. Methods in Phys. Res., B, 265 (2007) 146-149.

[5] M. Kim, and K. Saito, Radiat. Phys. Chem., 57 (2000) 167-172.

[6] M. Kim, S. Kiyohara, S. Konishi, S. Tsuneda, K. Saito, Sugo, J. Membr. Sci., 117 (1996) 33-38.

[7] S. Kiyohara, M. Sasaki, K. Saito, K., Sugita, T. Sugo, React. Funct. Poly., 31 (1996) 103-110.

[8] P. A. Kavakl1, N Seko, M. Tamada, Güven, J. Polym. Sci., 105 (2007) 1551-1558.

[9] S. Aoki, K. Saito, A. Jyo, A. Katakai, T. Suho, Anal Sci., 17 (2001)

[10] Y. Bondar, H. Y. Kim, S. K. Yoon, Lim. React. Funct. Polym., 58 (2004) 43-51

[11] A. Terada, A. Yuasa, S. Tsuneda, A. Hirata, A Katakai, M. Tamada, Coloids and Surface B, Biointerfaces 43(2005) 99-107.

[12] S. J. Park, Y. M. Kim, (2005). J. Porous. Mater., 12 (2005) 41-46.

[13] C. A. B. Nava-Ortiz, G. Burillo, Alvarez-Lorenzo, Radit. Phys. Chem., 78 (2009) 19-24

[14] M. Grasselli, M. L. Carbajal, F. Yoshii, T. Sugo, J. Appl. Polym. Sci., 87 (2003) 1646-1653.

[15] S. H. Choi, Y. H. Jeong, J. J. Ryoo, K. P. Lee. Radiat. Phys. Chem., 60 (2001) 503-511.

[16] J. M. Rosiak, Radiation Polymerization Polymer in Solution. Advances in Radiation Chemistry of Polymers, (2003) IAEA.

[17] N. Seko, N. T. Y. Ninh, M, Tamada, Radiat. Phys. Chem., 79 (2010) 22-26. 